University for Business and Technology in Kosovo

UBT Knowledge Center

UBT International Conference

2012 UBT International Conference

Nov 2nd, 9:00 AM - Nov 3rd, 5:00 PM

\title{
Dynamic Modeling and Analysis of Propulsion effect of 3 DoF robot
}

\author{
Ahmet Shala \\ University for Business and Technology, ahmetshala_2000@yahoo.com \\ Xhevahir Bajrami \\ Vienna University of Technology, xhevahirbajrami@hotmail.com
}

Follow this and additional works at: https://knowledgecenter.ubt-uni.net/conference

Part of the Computer Sciences Commons, and the Engineering Commons

\section{Recommended Citation}

Shala, Ahmet and Bajrami, Xhevahir, "Dynamic Modeling and Analysis of Propulsion effect of 3 DoF robot" (2012). UBT International Conference. 63.

https://knowledgecenter.ubt-uni.net/conference/2012/all-events/63

This Event is brought to you for free and open access by the Publication and Journals at UBT Knowledge Center. It has been accepted for inclusion in UBT International Conference by an authorized administrator of UBT Knowledge Center. For more information, please contact knowledge.center@ubt-uni.net. 


\title{
Dynamic Modeling and Analysis of Propulsion effect of 3 DoF robot
}

\author{
Ahmet Shala \\ University of Prishtina, Faculty of Mechanical Engineering \& \\ University for Business and Technology \\ Email: ahmetshala_2000@yahoo.com \\ Website: www.ahmetshala.tk \\ Xhevahir Bajrami \\ Doctoral Candidate from 03/2011 in Vienna University of Technology \\ Email: xhevahirbajrami@hotmail.com
}

Abstract-Dynamical Modeling of robots is commonly first important step of Modeling, Analysis and Control of robotic systems. This paper is focused on using Denavit-Hartenberg (DH) convention for kinematics and Newton-Euler Formulations for dynamic modeling of 3 DoF - Degree of Freedom of 3D robot. The process of deriving of dynamical model is done using Software Maple. Simulations are done using Matlab/Simulink for analysis of propulsion effect under Earth gravity when First Link rotates with 1000 rpm, second Link can move free in vertical direction and Third Link can rotates free around their rotations axle. Simulations results shows very good propulsion of proposed 3 DoF robot. Results are verified-compared with constructed model of 3 DoF robot using Working Model 3D Software.

Keywords: Kinematics, dynamics, robot, propulsion.

\section{DYNAMICAL MODELING OF 3 DOF ROBOT}

Dynamics is a huge field of study devoted to studying the forces required to cause motion. The dynamic motion of the manipulator arm in a robotic system is produced by the torques generated by the actuators. This relationship between the inpu $t$ torques and the time rates of change of the robot arm components configurations, represent the dynamic modeling of the robotic system which is concerned with the derivation of the equations of motion of the manipulator as a function of the forces and moments acting on. So, the dynamic modeling of a robot manipulator consists of finding the mapping between the forces exerted on the structures and the joint positions, velocities and accelerations. A good model has to satisfy two conflicting objectives. It must include enough detail to represent the real behavior of the robot with sufficient accuracy, and it should permit an efficient, stable evaluation not only of the model equations but als o of their derivatives that are needed in optimization.

The availability of the dynamic model is very useful for mechanical design of the structure, choice of actuators, determination of control strategies, and computer simulation manipulator motion.

A robot manipulator is basically a positioning device. To control the position we must know the dynamic properties of the manipulator in order to know how much force to exert on it to cause it to move: too little force and the manipulator is slow to react; too much force and the arm may crash into objects or oscillate about its desired position.

Deriving the dynamic equations of motion for robots is not a simple task due to the large number of degrees of freedom and nonlinearities present in the system. This part is concerned with the development of the dynamic model for 3 Dof robot and their kinematics and dynamics equations. 


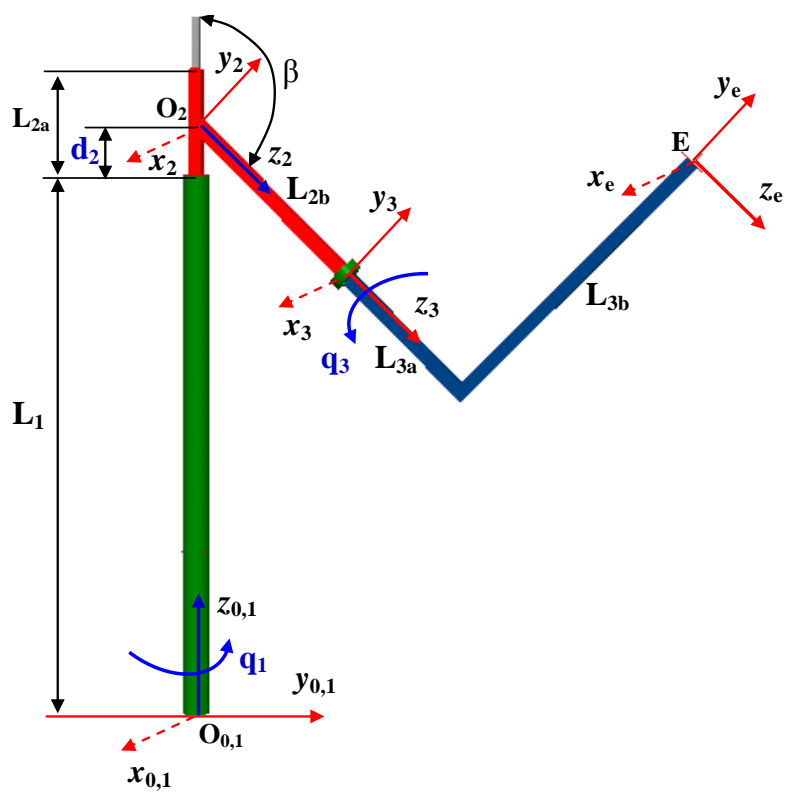

Figure 1a. Symbolic representation - Axes rotations for Denavit-Hartenberg parameters

From Figure 1a, can be created Table 1 of Denavit-Hartenberg parameters for 3 DoF robot

Table 1. Denavit-Hartenberg parameters for 3 DoF robot

\begin{tabular}{|c|c|c|c|c|}
\hline Link \# & $\boldsymbol{a}_{\boldsymbol{i}}$ & $\boldsymbol{\alpha}_{\boldsymbol{i}}$ & $\boldsymbol{d}_{\boldsymbol{i}}$ & $\boldsymbol{\theta}_{\boldsymbol{i}}$ \\
\hline 1 & 0 & 0 & $d_{1}$ & $q_{1}{ }^{{ }}$ \\
\hline 2 & 0 & $-\beta$ & $d_{2}{ }^{*}$ & 0 \\
\hline 3 & 0 & 0 & $L_{3 a}$ & $q_{3}{ }^{*}$ \\
\hline
\end{tabular}

* Joint variable

Denavit-Hartenberg transformation matrix for adjacent coordinate frames, $\boldsymbol{i}$ and $\boldsymbol{i}-1$.

$$
A_{i}=\left[\begin{array}{cccc}
\cos \left(\theta_{i}\right) & -\cos \left(\alpha_{i}\right) \cdot \sin \left(\theta_{i}\right) & \sin \left(\alpha_{i}\right) \cdot \sin \left(\theta_{i}\right) & a_{i} \cdot \cos \left(\theta_{i}\right) \\
\sin \left(\theta_{i}\right) & \cos \left(\alpha_{i}\right) \cdot \cos \left(\theta_{i}\right) & -\sin \left(\alpha_{i}\right) \cdot \cos \left(\theta_{i}\right) & a_{i} \cdot \sin \left(\theta_{i}\right) \\
0 & \sin \left(\alpha_{i}\right) & \cos \left(\alpha_{i}\right) & d_{i} \\
0 & 0 & 0 & 1
\end{array}\right]
$$

Orthogonal rotation matrix $\boldsymbol{R}_{\boldsymbol{i}}$ which transforms a vector in the i-th coordinate frame to a coordinate frame which is parallel to the (i-1)-th coordinate frame is first $3 \times 3$ sub-matrices of $\boldsymbol{A}_{\boldsymbol{i}}$ :

$$
R_{i}=\left[\begin{array}{ccc}
\cos \left(\theta_{i}\right) & -\cos \left(\alpha_{i}\right) \cdot \sin \left(\theta_{i}\right) & \sin \left(\alpha_{i}\right) \cdot \sin \left(\theta_{i}\right) \\
\sin \left(\theta_{i}\right) & \cos \left(\alpha_{i}\right) \cdot \cos \left(\theta_{i}\right) & -\sin \left(\alpha_{i}\right) \cdot \cos \left(\theta_{i}\right) \\
0 & \sin \left(\alpha_{i}\right) & \cos \left(\alpha_{i}\right)
\end{array}\right]
$$

for $\mathrm{i}=1,2, \ldots, \mathrm{N}$, where $R_{N+1}=E=\operatorname{diag}(1)$

\section{DYNAMIC EQUATIONS - NEWTON-EULER FORMULATION}

Dynamics of robot is the study of motion with regard to forces (the study of the relationship between forces/torques and motion). A dynamic analys is of a manipulator is useful for the following purposes:

1- It determines the joint forces and torques required to produce specified end-effector motions (the direct dynamic problem). 
2- It produces a mathematical model which simulates the motion of the manipulator under various loading conditions (the inverse dynamic problem) and/or control schemes.

3- It provides a dynamic model for use in the control of the actual manipulator.

Dynamic modelling of mechanical structures can be a complex problem. In robotics, more specifically, in manipulators, there a re two methodologies used for dynamic modelling:

a) Newton-Euler formulationb) Lagrange-Euler formulation.

The Newton-Euler formulation [1] shown in equations (1)-(9) computes the inverse dynamics (ie., joint torques/forces from joint positions, velocities, and accelerations) bases on two sets of recursions: the forward and backward recursions. The forward recursions (1)-(3) transform the kinematics variables from the base to the end-effector. The initial conditions (for $i=0$ ) assume that the manipulator is at rest in the gravitational field. The backward recursions (4)-(9) transform the forces and moments from the end-effector to the base, and culminate with the calculation of the joint torques/forces.

Angular velocity of the $\boldsymbol{i}$-th coordinate frame

$$
\omega_{i+1}=\left\{\begin{array}{l}
R_{i+1}^{T} \cdot\left[\omega_{i}+z_{0} \cdot \dot{\theta}_{i+1}\right] \quad \text { if joint is rotational } \\
R_{i+1}^{T} \cdot \omega_{i} \quad \text { if joint is translational }
\end{array}\right.
$$

where: $z_{0}=\left[\begin{array}{lll}0 & 0 & 1\end{array}\right]^{T}$

Angular acceleration of the $i$-th coordinate frame

$$
\dot{\omega}_{i+1}=\left\{\begin{array}{l}
R_{i+1}^{T} \cdot\left[\dot{\omega}_{i}+z_{0} \cdot \ddot{\theta}_{i+1}+\omega_{i} \times\left(z_{0} \cdot \dot{\theta}_{i+1}\right)\right] \\
\quad \text { if joint is rotational } \\
R_{i+1}^{T} \cdot \dot{\omega}_{i} \\
\quad \text { if joint is translational }
\end{array}\right.
$$

Linear acceleration of the $\boldsymbol{i}$-th coordinate frame

$$
\dot{v}_{i+1}=\left\{\begin{array}{l}
R_{i+1}^{T} \cdot \dot{v}_{i}+\dot{\omega}_{i+1} \times p_{i+1}+\omega_{i+1} \times\left(\omega_{i+1} \times p_{i+1}\right) \\
\text { if joint is rotational } \\
R_{i+1}^{T}\left[\dot{v}_{i}+z_{0} \ddot{d}_{i+1}+2 \omega_{i} \mathrm{x}\left(z_{0} \dot{d}_{i+1}\right)\right]+ \\
+\dot{\omega}_{i+1} \mathrm{x} p_{i+1}+\omega_{i+1} \mathrm{x}\left(\omega_{i+1} \mathrm{x} p_{i+1}\right) \\
\text { if joint is translational }
\end{array}\right.
$$

where: $p_{i}=\left[\begin{array}{lll}a_{i} & d_{i} \cdot \sin \left(\alpha_{i}\right) & d_{i} \cdot \sin \left(\alpha_{i}\right)\end{array}\right]^{T}$ is position of the $\boldsymbol{i}$-th coordinate frame with respect to the $(i-1)$-th coordinate frame.

Initial conditions: $\omega_{0}=\dot{\omega}_{0}=v_{0}=0$;

Gravitational acceleration: $\dot{v}_{0}=\left[\begin{array}{lll}g_{x} & g_{y} & g_{z}\end{array}\right]^{T}$.

Linear acceleration of the centre-of-mass of lin $\mathrm{k} \boldsymbol{i} a_{i}=\dot{\omega}_{i} \times s_{i}+\omega_{i} \times\left(\omega_{i} \times s_{i}\right)+\dot{v}_{i}$

where: $s_{i}$ is position of centre-of-mass of link $i$

Net force exerted on link $i$ :

$$
F_{i}=m_{i} \cdot a_{i}
$$

Net moment exerted on link $\boldsymbol{I}$

$$
N_{i}=I_{i} \dot{\omega}_{i}+\omega_{i} \times\left(I_{i} \cdot \omega_{i}\right)
$$

where $I_{i}=\left[\begin{array}{ccc}I_{i x x} & 0 & 0 \\ 0 & I_{i y y} & 0 \\ 0 & 0 & I_{i z z}\end{array}\right]$

$\boldsymbol{I}_{\boldsymbol{i}}$ is moment of inertia tensor of link $\boldsymbol{i}$ about the centre-of-mass of link $\boldsymbol{i}$ (parallel to the $\boldsymbol{i}$-th coordinate frame), with only principal inertias $\boldsymbol{I}_{i x \boldsymbol{x}}, \boldsymbol{I}_{i y \boldsymbol{y}}$ and $\boldsymbol{I}_{i z z}$. Because of symmetry of link frames, cross -inertias can be used zero.

Force exerted on link $\boldsymbol{i}$ by link $\boldsymbol{i}-\mathbf{1}$ :

$$
f_{i}=R_{i+1}^{T} \cdot f_{i+1}+F_{i}
$$


Moment exerted on link $i$ by link $i-1$

$$
n_{i}=R_{i+1}^{T} \cdot n_{i+1}+p_{i} \times f_{i}+N_{i}+s_{i} \times F_{i}
$$

Joint torque/force at joint $i$ :

$$
\tau_{i}= \begin{cases}n_{i}^{T} \cdot\left(R_{i+1}^{T} \cdot z_{0}\right) & \text { if joint is rotational } \\ f_{i}^{T} \cdot\left(R_{i+1}^{T} \cdot z_{0}\right) & \text { if joint is translational }\end{cases}
$$

Modeling of 3 DoF robot is done using Maple 15 software, equations are converted for Matlab use.

\section{SIMULATION RESULTS OF EXISTENCE OR NON-EXISTENCE OF THE DESIRED PROPULSION EFFECT!}

For analysis of existence or non-existence of propulsion is done test as in view.

Link 3 (L-form) rotates free from vertical initial position. One part of Link 2 is vertical and second part is under $135^{\circ}$ with verticals. Link 2 can move free up-down and is supported free on Link 1.

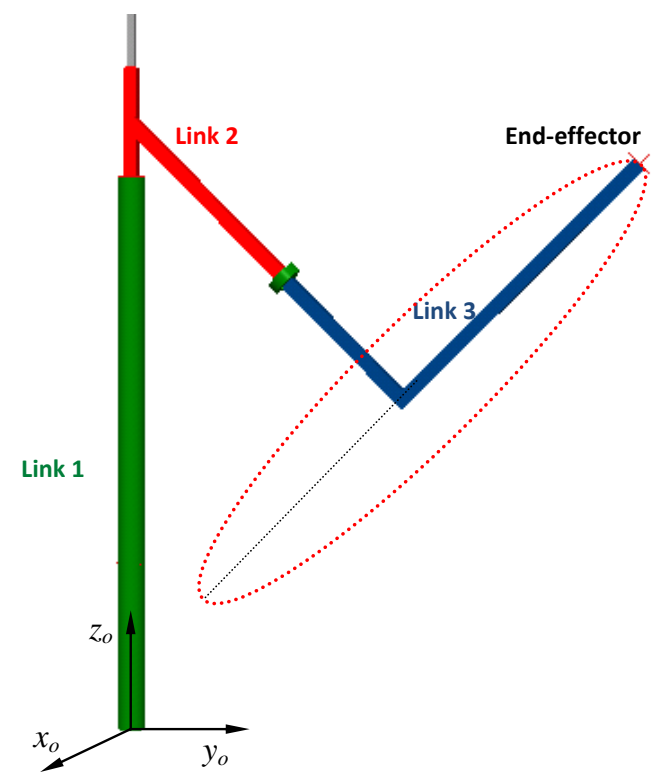

Figure 1b. Robot 3 DoF in initial position.

From the simulation based on previous conditions, in Figure 2 are represented diagram of Contact Force between Link 2 and Link 1 when Link 3 rotates free from initial position ( 0.1 deg deviated because of theoretical stability) and diagram of orient ation of Link 3 respectively $\mathrm{q}_{3}$.

\section{Main dimensions of robot}

Link masses: $\mathrm{m}_{1}=10 \mathrm{~kg}, \mathrm{~m}_{2}=10 \mathrm{~kg}, \mathrm{~m}_{3}=15 \mathrm{~kg}$.

Link lengths: $\mathrm{L}_{1}=\mathrm{d}_{1}=1.0 \mathrm{~m}, \mathrm{~L}_{2 \mathrm{a}}=2 \cdot \mathrm{d}_{2}=0.2 \mathrm{~m}, \mathrm{~L}_{2 \mathrm{~b}}=0.4 \mathrm{~m}, \mathrm{~L}_{3 \mathrm{a}}=0.3 \mathrm{~m}, \mathrm{~L}_{3 \mathrm{~b}}=\mathrm{d}_{3}=0.6 \mathrm{~m}$ 


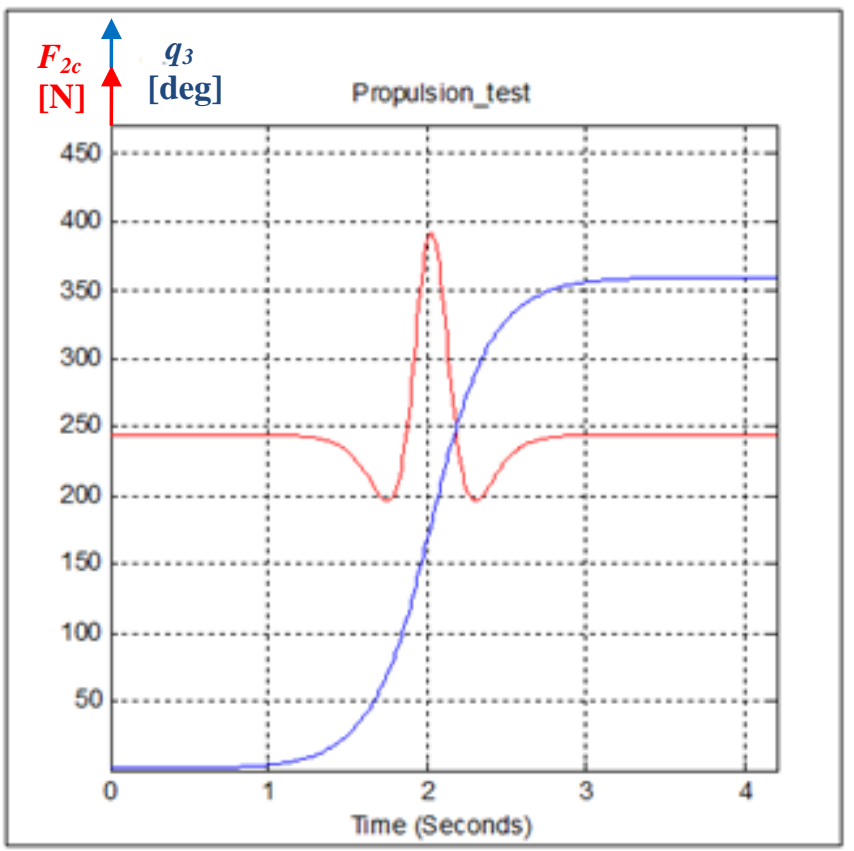

Figure 2. Contact Force between Link 2 and Link 1 and orientation $\mathrm{q}_{3}$ of Link 3.

From Figure 2 can be seen that Contact Force has its maximum $F_{c 2 m a x}=392.16 \mathrm{~N}$ for $\mathrm{q}_{3}=180^{\circ}$.

\section{SIMULATION OF PROPULSION OF DYNAMICAL MODEL OF 3D OF ROBOT}

- Angle between two parts of Link 2 is fixed to $45^{\circ}$;

- Link 3 starts in vertical position (down normal to $\mathrm{x}_{0}-\mathrm{y}_{0}$ plane) and swings free

- Link 2 is free supported on Link 1

- Link 1 is turned up to $1000 \mathrm{rpm}$

- Steel is assumed for cylinder/prism masses and moments of inertia.

Main characteristic of this Case: start position of Link 3, $\mathrm{q}_{3}=\mathrm{pi}=180^{\circ}$

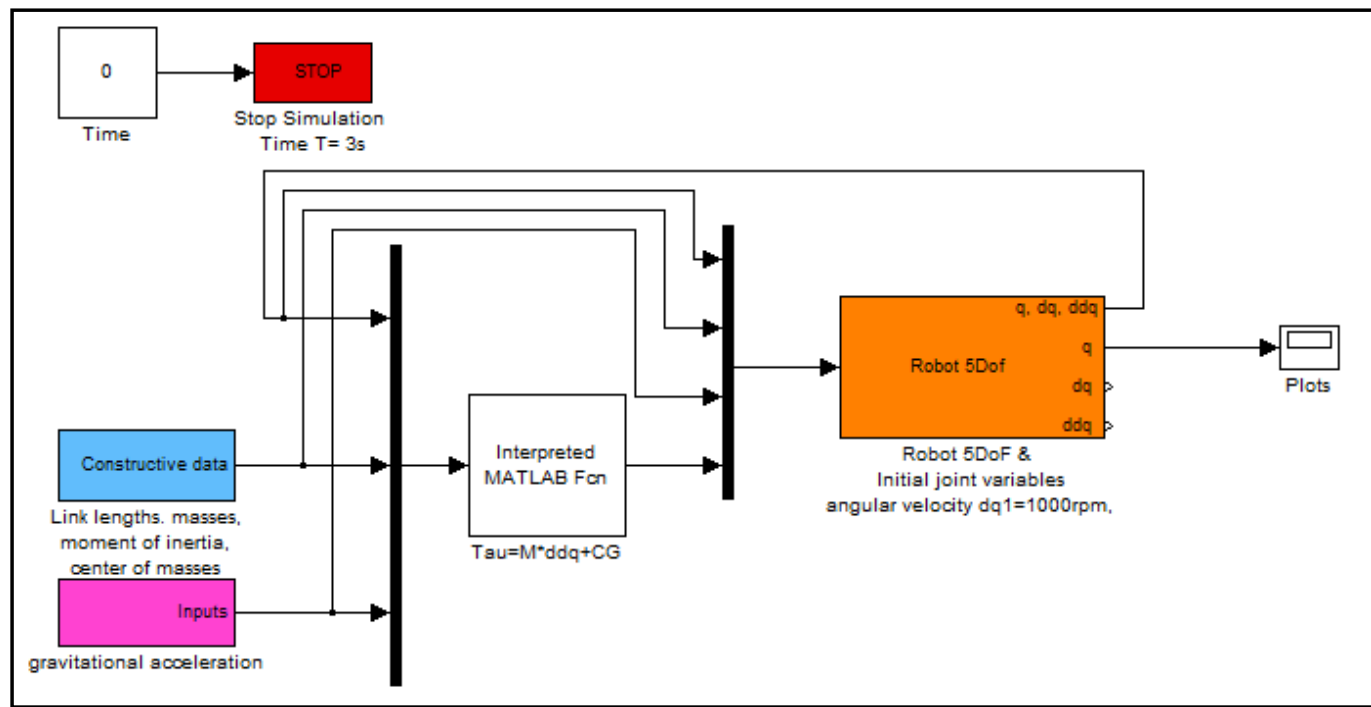

Figure 3. Simulation scheme of robot, propulsion effect for initial position of Link 3 under $\mathrm{q}_{3}=180^{\circ}$ 
Propulsion is result of fast rotation of Link 1, $1000 \mathrm{rpm}$, and rotation-oscillation of Link 3, which results from contact force between Link 2 and Link 1, only for the time when these two Links are in contact, when Link 2 starts to move up $\left(\mathrm{d}_{2}>1.1\right)$ contact force is zero.

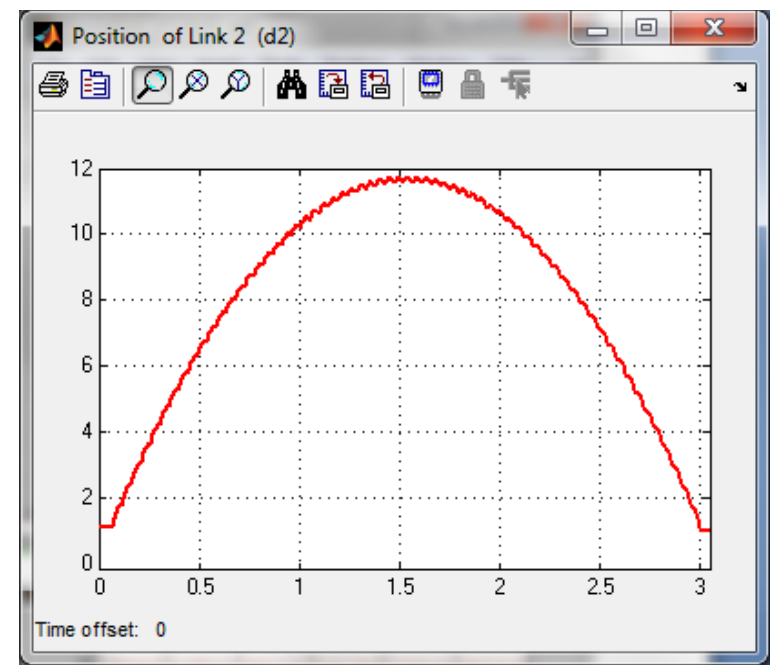

Figure 4. Vertical movement of Link 2

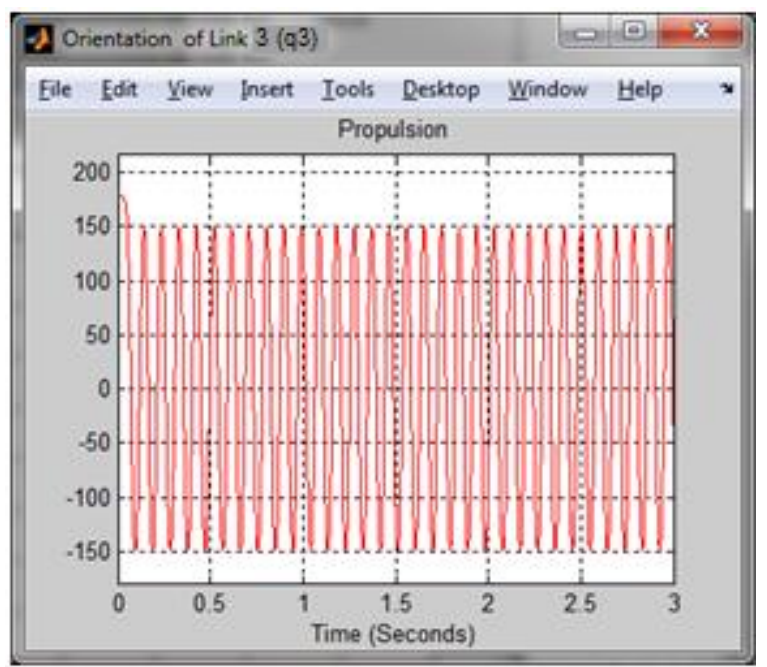

Figure 5. Orientation of Link 3 around its rotation axe, $\mathrm{q}_{3}$

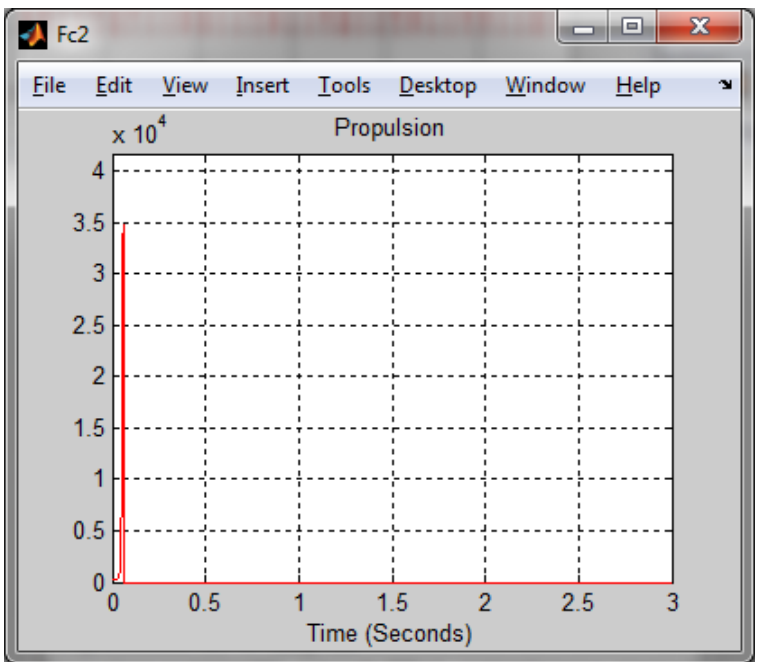

Figure 6. Contact Force between Link 2 and Link 1 


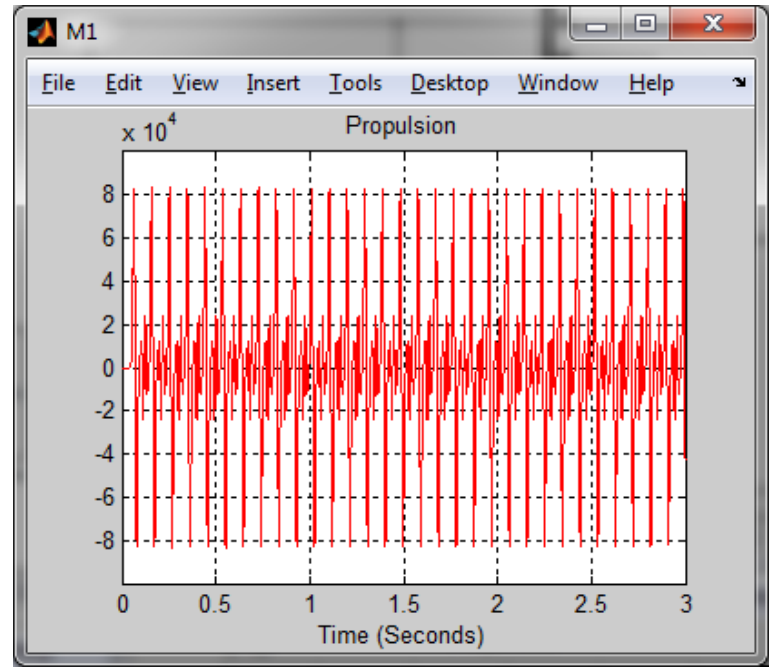

Figure 7. Joint Torque on Link 1, Motor M1.

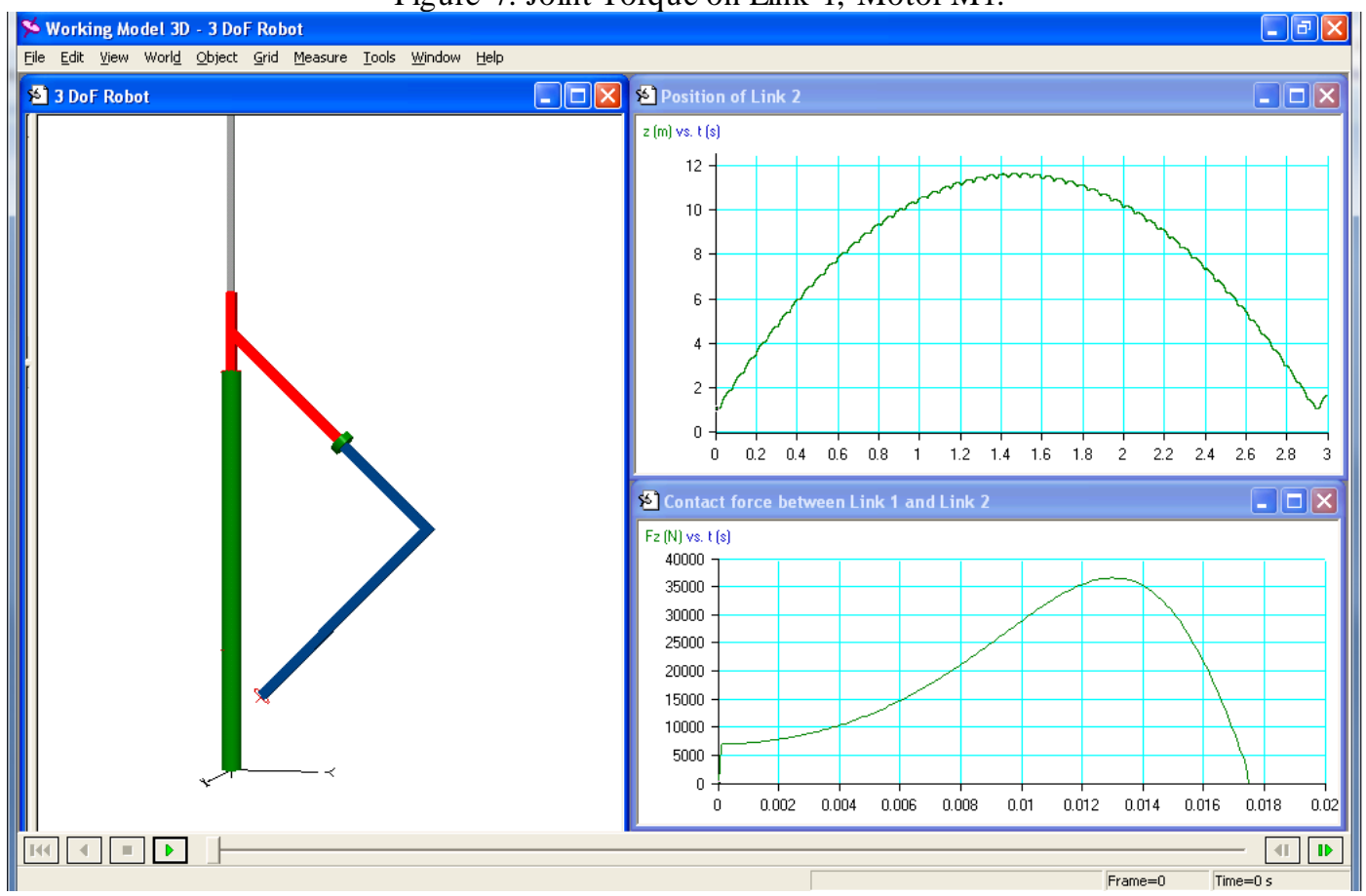

Modeling and simulations using Working Model 3D software

Contact Force $F_{c 2}$ in the start of simulation is $245.1625 \mathrm{~N}=\left(\mathrm{m}_{2}+\mathrm{m}_{3}+\mathrm{m}_{4}+\mathrm{m}_{5}\right)^{\circ} \mathrm{g}$. This is reaction force of contact between Link 2 and Link 1. When Link 2 starts moving up, Contact force has its maximum and after that during movement of Link 2, no contact between Link 2 and Link 1, this mean that contact force is zero until Link 2 is coming back and strike the Link 1.

In Figure 8 is represented Contact force $\mathrm{F}_{\mathrm{c} 2}$ and reaction force $\mathrm{F}_{\mathrm{r} 2}$ (like joint 2 is rigid joint). 


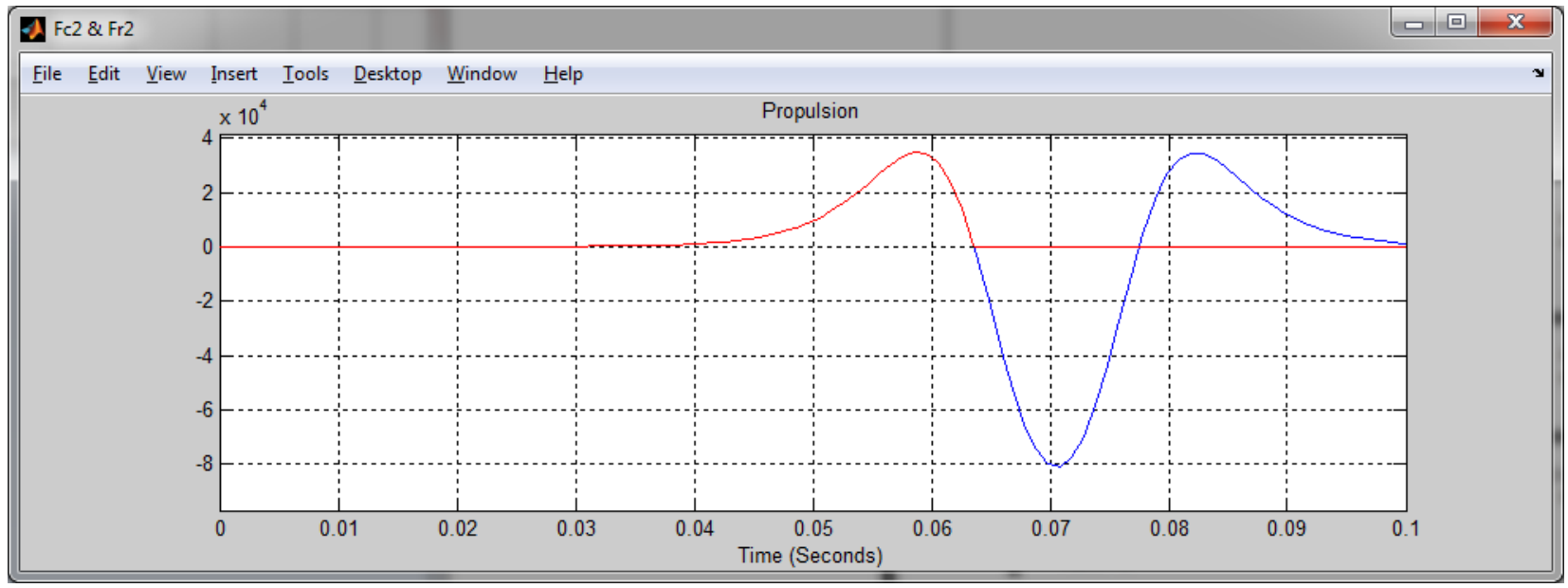

Figure 8. Contact force $\mathrm{F}_{\mathrm{c} 2}$ and Reaction force $\mathrm{F}_{\mathrm{r} 2}$

Propulsion in this case is result of difference of real reaction force which is static + dynamic reaction force during movement, as is represented in Figure 2.

\section{CONCLUSIONS}

Based on simulation results for case $\left(\mathbf{q}_{4}\right)_{0}=\mathbf{1 8 0}^{\circ}$ can be concluded:

- $\mathrm{d}_{2}$ is growing significantly from initial position $1.1 \mathrm{~m}$ to around $11.5 \mathrm{~m}$.

- Link 3 oscillates around own oscillation axe.

- For this case is clear that exist propulsion effect and based on diagram of Contact Force in Figure 2 and other simulations tests which are done this is the biggest propulsion of robot.

\section{REFERENCE}

Luh, J. Y. S., Walker, M. W. and Paul, R. P.; On-Line Computational Schemefor Mechanical Manipulators. Journal of Dynamic System s, Measurement, and Control 102(2):69-76, June, 1980

Brady, M., et al. (editors). Robot Motion: Planning and Control. MIT Press, Cambridge, MA, 1982.

Khosla, Pradeep, "Estimation of Robot Dynamics Parameters: Theory and Application". Institute for Software Research. Paper 651. http://repository.cmu.edu/isr/651, Carnegie Mellon University, 1987. 